\title{
Article
}

\section{Advancing an understanding of design cognition and design metacognition: Progress and prospects}

\author{
Ball, Linden and Christensen, Bo T.
}

Available at http://clok.uclan.ac.uk/31276/

Ball, Linden ORCID: 0000-0002-5099-0124 and Christensen, Bo T. (2019) Advancing an understanding of design cognition and design metacognition: Progress and prospects. Design Studies, 65 . pp. 35-59. ISSN 0142-694X

It is advisable to refer to the publisher's version if you intend to cite from the work. http://dx.doi.org/10.1016/j.destud.2019.10.003

For more information about UCLan's research in this area go to http://www.uclan.ac.uk/researchgroups/ and search for < name of research Group>.

For information about Research generally at UCLan please go to http://www.uclan.ac.uk/research/

All outputs in CLoK are protected by Intellectual Property Rights law, including Copyright law. Copyright, IPR and Moral Rights for the works on this site are retained by the individual authors and/or other copyright owners. Terms and conditions for use of this material are defined in the policies page.

\section{CLoK}

Central Lancashire online Knowledge www.clok.uclan.ac.uk

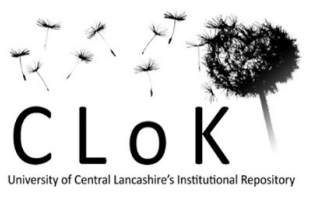


This is the final version of a manuscript that has been accepted for publication in Design Studies. The published version of record that will appear in the journal in November 2019 may differ from this manuscript.

\title{
Advancing an Understanding of Design Cognition and Design Metacognition: Progress and Prospects
}

\author{
Linden J. Ball* \\ School of Psychology \\ University of Central Lancashire \\ Preston PR1 2HE \\ UK \\ Phone: +44 (0)1772 893421 \\ Email: LBall@uclan.ac.uk
}

\section{Bo T. Christensen}

Department of Marketing Copenhagen Business School Solbjerg Plads 3, 2000 Frederiksberg C

Denmark

Phone: +45 38152123

Email: bc.marktg@cbs.dk

* Corresponding Author 


\title{
Advancing an Understanding of Design Cognition and Design Metacognition: Progress and Prospects
}

\begin{abstract}
In this article we review progress that has been made in advancing a theoretical understanding of design cognition and design metacognition. We identify a high level of consistency in empirical findings, including good evidence for core design strategies such as conjecture-based problem formulation, problem-solution co-evolution, analogical reasoning, mental simulation and fixated solution generation. A further consistent theme to emerge in our review concerns the central role played by metacognitive monitoring and control processes in ensuring the effective deployment of design strategies in response to designers' fluctuating feelings of uncertainty. We argue that a metacognitive perspective on design cognition is critical for developing a comprehensive understanding of strategic processing in design, additionally engendering many new avenues for important future research.
\end{abstract}

\section{Keywords:}

design cognition; design metacognition; design strategy; design problem(s); information processing 


\section{Advancing an Understanding of Design Cognition and Design Metacognition: Progress and Prospects}

The ambition to develop design as a discipline originated in the 1960s (see Cross, 1993, 2007, 2018), strongly fuelled by the desire of cognitive scientists (e.g., Simon, 1969) to establish 'a science of design' using empirical evidence and formal theorising to model problem solving in this important area of real-world endeavour. Since the 1960s the commitment to advance a scientific understanding of design from a cognitive perspective has continued apace, with a core focus on examining how information is manipulated by reasoning processes to generate new solution ideas, judgments and decisions. We present here a review of the extant research on design cognition, albeit a review that is restricted to what we believe are key phenomena given the sheer abundance of research that has taken place on this topic to date. Another factor driving our selective coverage of the literature concerns our desire to focus primarily on findings that have been replicated across different studies. As noted by Cash (2018), much design research suffers from weak methodological and theoretical rigour, including a lack of adequate controls, leading to inconsistent results and an inability to derive clear-cut causal interpretations. We finally note that in reviewing the literature we adopt a domain-independent view of design, extracting findings relating to design cognition that appear to generalise across different design fields. As such, we are not so concerned about any nuances of cognitive processing that seem to be specific to particular design areas.

The research that we review has primarily used two methodologies to address the nature of design cognition (for examples of both approaches see Cross, Christiaans, \& Dorst, 1996; for more detail concerning these methods see Christensen \& Ball, 2014). One key method involves asking lone designers to 'think-aloud' whilst engaged in design work. This gives rise to a verbal protocol that can be transcribed, coded and analysed to reveal aspects of thinking and reasoning. Another important method involves the researcher monitoring team-based design conversations, with the resulting transcripts again being coded and analysed to elicit an understanding of the socio-cognitive dimensions of team-based design thinking. A more limited subset of the research we review has used experimental methods, involving random allocation of designers to different conditions to determine the causal impact of manipulated variables on performance outcomes (e.g., creative ideation or design quality).

In summarising important findings regarding design cognition, we aim to demonstrate that a major concern is to understand how designers select and deploy design strategies to navigate through the inherent 'uncertainty' that pervades real-world design problems because of their 'ill-defined' (Simon, 1973) or 'wicked' (Rittel \& Webber, 1973) nature. We will show that designers' abilities to steer a path through such uncertainty by careful strategy selection enables them to progress effectively from an ill-defined design problem to an end-point of having a high-quality design solution. We contend, moreover, that in striving to understand strategic processing in design, researchers are fundamentally concerned not just with design cognition but also with design 'metacognition'. Metacognition refers to processes that continually monitor and control cognition so that effective strategies can be maintained whilst ineffective ones can be abandoned and replaced (Ackerman \& Thompson, 2017, 2018). In our view, metacognition is an overlooked aspect of cognitive processing in design, despite being central to deriving a full understanding of every aspect of designers' ongoing activity in attaining an implementable design solution. In concluding our review, we argue that viewing design cognition through a metacognitive lens can enable an integrated understanding to be derived of the way in which strategies change over the timecourse of a design task in 
response to designers' fluctuating feelings of uncertainty. We also suggest that bringing the concept of design metacognition to centre stage offers many fresh ideas for future design research.

\section{Problem formulation processes in design}

Design is not simply a case of 'business-as-usual' problem solving given the typically extensive information concerning requirements and constraints that is either loosely specified in the design brief or is simply absent altogether, making design problems some of the most ill-defined tasks tackled in professional contexts. What this means in practice is that designers must, of necessity, spend some initial time reflecting on what the problem is - a process that Cross (2001) captures neatly with the term 'problem formulation', whereby some initial assumptions are made about requirements and constraints. As Ullman, Dietterich, and Stauffer (1988) observed in studies of expert designers in mechanical engineering, numerous constraints are introduced early based on domain knowledge, whilst others are derived during the problem-solving process as designers explore solution concepts.

Notwithstanding the evidence that at least some initial problem formulation needs to take place in design, what has also been consistently seen in studies of expert designers is that this process in invariably incomplete, fluid and time-limited, with designers often being more interested in jumping toward the exploration of ideas for potential solutions rather than trying to formulate all aspects of the problem up-front (e.g., Eastman, 1970; Lawson, 1979; Lloyd \& Scott, 1994). What is fascinating, too, is that experienced designers are so adept at handling problem formulation in a fluid and partial way that they will do this even when design problems are relatively well defined. In other words, experienced designers still treat welldefined design problems $a s$ if they are ill-defined, relaxing or redefining constraints and amending or augmenting goals (e.g., Akin, 1978; Thomas \& Carroll, 1979), seemingly being averse to engaging in business-as-usual problem solving even when it is possible.

\subsection{Individual differences in problem formulation}

Other studies examining problem formulation in design have focused on individual variation in strategies, including differences between expert and novice designers. For example, Christiaans and Dorst (1992) observed that junior design students tended not to gather much information about the given problem, instead solving what was essentially a simpler problem because of a lack of awareness of key constraints and difficulties. In contrast, Christiaans and Dorst found that senior design students could be sub-divided into two types: (i) those who tended to get enmeshed in extensive, initial information gathering to the detriment of progressing to solution generation, which severely limited success; and (ii) those who tended to gather less initial information and were more successful in generating good-quality solutions. In a subsequent study of engineering design students, Atman, Chimka, Bursic, and Nachtmann (1999) investigated the problem solving of freshmen with little design experience and senior students with more advanced design experience. Freshmen who spent a large proportion of time formulating the problem (what Atman et al., referred to as 'problem scoping') produced poor designs compared to freshmen who spent less time on this activity, with the former seemingly becoming stuck trying to define the problem (cf. Christiaans \& Dorst, 1992). The seniors not only engaged more extensively in problem scoping than the freshmen, but this information-gathering and assumption-making was more successful, leading to better design solutions. 
In sum, there is clear evidence for individual differences in problem formulation, with successful designers being those who spend sufficient yet effective time gathering initial information and defining goals and constraints rather than spending excessive time on such activities that is unproductive for problem-solving progress. Such strategic differences in problem formulation seem to be linked to designers' experience, being acquired as a designer becomes adept at understanding how best to balance problem formulation and solution development to achieve successful design outcomes. What is less clear is the nature of the moment-by-moment metacognitive monitoring and control processes that drive decisions to continue with problem formulation or to switch to solution development, which represents a fruitful avenue for research.

\subsection{Solution conjectures and problem framing}

Studies of individual differences in problem formulation suggest that whilst some degree of problem-definition activity is critical for design success it is equally important that activity progresses quickly toward solution generation. Indeed, there is good evidence that speculative solution ideas are themselves very useful for helping to formulate design problems, with such ideas effectively serving as 'conjectures' that allow designers to clarify their understanding of the problem. For example, Darke (1979), in her studies of renowned architects, showed that they generated initial solution concepts as 'primary generators', which acted as guiding conjectures to provide 'a way into the problem', whilst also enabling the architects to explore and understand the problem by testing the adequacy of an initial solution concept (see Lloyd \& Scott, 1995, for similar observations in the architectural domain, which they refer to as the generation of 'problem paradigms').

A solution-oriented, conjectural approach to designing makes good sense, as having a solution idea in mind allows the designer to check whether it meets problem requirements and constraints. This process will invariably reveal that certain information is missing or poorly articulated such the client can be consulted for clarification or else feasible assumptions can be made. The view that design revolves around the generation of solution conjectures also resonates with the notion that creative idea generation in design in primarily driven by 'abductive reasoning' (e.g., Cramer-Petersen, Christensen, \& Ahmed-Kristensen, 2019; Dong, Lovallo, \& Mounarath, 2015; Dorst, 2011; Roozenburg, 1993), which is defined as 'inference to the best explanation' (e.g., Schurz, 2008) because the goal is to provide a suitable conjecture to account for available data. The link between abductive reasoning and creative design should be apparent, as the latter activity fundamentally involves generating an effective solution conjecture to meet requirements and constraints.

Darke's (1979) concept of a primary generator that acts as guiding conjecture to enable design advancement also aligns closely with Schön's (1983) concept of a problem 'frame'. According to Schön, an expert designer, having selected features of a problem to attend to (a process referred to as 'naming') will then identify aspects of the solution they wish to explore and develop (a process described as 'framing'). Schön (1983) also clarified that such framing is rarely conducted in a single burst of activity at the start of design work, but instead occurs throughout the design process, as confirmed in many subsequent studies (e.g., Adams, Aleong, Goldstein, \& Solis, 2018; Goel \& Pirolli, 1992; Valkenburg \& Dorst, 1998). In their study of team design, for example, Valkenburg and Dorst (1998) identified five different frames that were used sequentially by a successful industrial design team tackling a given project. In contrast, the unsuccessful team relied on a single frame and spent a much greater proportion of time understanding the problem rather than developing solution concepts. 
As McDonnell (2018) notes, a key benefit of a problem frame as conceptualised by Schön (1983) is that it enables designers to impose order and coherence on a complex, uncertain and unstable design situation so that good design decisions can be made. In this way, effective framing enforces what McDonnell refers to as a 'discipline', by inviting and supporting certain design moves and ruling out others. The success of design work will, therefore, be crucially dependent on the designer's effective operationalisation of a frame that provides sufficient room for creative exploration whilst also providing sufficient constraints to enable a focused solution to progress. McDonnell (2018) discusses a case study whereby a lack of 'frame discipline' led to impoverished design work, whilst Lloyd and Oak (2018) provide evidence for how a clearly articulated and systematically co-developed problem frame can enable a design team to structure and anchor collaborative activity to achieve productive design development.

\subsection{Problem-solution co-evolution}

The role played by solution-focused conjectures in facilitating designers to interrogate and understand design problems underscores the way in which design problems are dynamic and mutable and can continually be informed by emerging solution ideas throughout the timecourse of design. This close interplay between problem formulation and solution generation has led to the theoretical proposal that designing should be viewed as a process of 'problem-solution co-evolution', whereby the designer explores two conceptual spaces, a 'problem space' and a 'solution space', with each informing the other (e.g., Cross \& Dorst, 1998; Dorst \& Cross, 2001). This co-evolution view of design was originally espoused by Maher (e.g., Maher, 1994, 2000; Maher \& Poon, 1995, 1996; Poon \& Maher, 1997), who drew on the biological concept of two species interacting so closely that their evolutionary fitness is co-dependent. By evoking this metaphor from nature, Maher advanced a computational understanding of how design problems and solutions can be modelled as evolving separately whilst having a mutual effect on one another (see Dorst, 2019, for contemporary considerations relating to modelling co-evolution).

The concept of problem-solution co-evolution in design gained further traction following Dorst and Cross's (2001) study that analysed verbal-protocol data from nine experienced industrial designers working individually to create a litter-disposal system for adoption in a new Netherlands train. This investigation revealed that designers simultaneously refined both their problem formulation and their solution ideas through a process of analysis, synthesis and evaluation that iterated between the problem space and the solution space. Furthermore, creative ideation did not arise in the form of a 'creative leap' from the problem to the solution, but instead involved the building of a 'bridge' between the problem space and the solution space (see Cross, 1997, for prior, related findings). The construction of such bridges appeared to be triggered by the designer's identification of 'surprising' or 'interesting' information in the design brief or associated documents. In this respect Dorst and Cross draw an important conceptual link to Schön's (1983) notion of problem framing by proposing that a creative event arises when a problem-solution pairing is 'framed'. Dorst and Cross additionally contend that studies of outstanding designers (e.g., Cross \& Clayburn Cross, 1998) confirm that problem-solution framing ability is critical for designers' attainment of the very highest levels of performance in creative design.

Maher and Tang (2003) also presented empirical evidence for problem-solution co-evolution, reporting one study in which senior student designers thought aloud whilst designing a novel 
product and another study involving experienced architects being tasked with designing a house, who described their thought processes retrospectively. These studies revealed that coevolution transitions often manifested as temporal oscillations between problem requirements and solutions until satisfactory solutions were identified. Despite the appeal of the problemsolution co-evolution concept in design-cognition research, Wiltschnig, Christensen, and Ball (2013) noted that the studies reported by Maher and Tang (2003) and Dorst and Cross (2001) suffer from a potential lack of ecological validity as they involved laboratory observations of time-limited design activities with individual designers. In response to these concerns, Wiltschnig et al. conducted a study of team-based design in a professional design context where the task spanned 2 years and involved 19 expert engineering designers organised into smaller sub-groups focusing on design sub-problems. The results established the generality of problem-solution co-evolution in naturally-occurring design collaboration, with $12 \%$ of design activity being structured around co-evolution episodes. In addition, Wiltschnig et al. corroborated the prediction that co-evolution involves various directional transitions between problem and solution spaces. Although co-evolution was dominated by requirements analysis leading to solution attempts ( $73 \%$ of episodes) there were also numerous instances of solution attempts sparking requirements analysis (19\% of episodes), which often resulted in requirement changes. This evidence attests to the bi-directional nature of co-evolution in realworld design and its capacity to modify aspects of the problem space through processes whereby requirements are reinterpreted, altered, deleted or added.

Wiltschnig et al.'s (2013) study additionally revealed the extent to which co-evolution arises from interactive processing between two or more members of the design team. Their analysis showed that $67 \%$ of co-evolution episodes were collaborative, with designers feeding off one another's proposals when formulating problems and generating solution possibilities. The team leader also played a vital role in catalysing co-evolution episodes, which resonates with Ball and Ormerod's (2000) observation that team managers deploy a range of tactics to ensure effective problem formulation and design development. Such tactics appear to reflect the high degree of metacognitive awareness of expert team managers regarding how to motivate and control ongoing design to achieve successful problem formulations and solution outcomes.

\section{Solution generation and solution evaluation processes in design}

Our foregoing examination of problem-formulation processes in design revealed how the illdefined nature of design problems necessitates a highly solution-focused design approach, with solution ideas acting as conjectures that inform a deeper understanding of the problem whilst also serving to frame ongoing activity. The complex, ill-defined nature of design problems also means that design activity rarely involves an attempt to find an 'optimal' solution, as the investment of time and effort would be prohibitive. In addition, it is unlikely that a designer would even know if an optimal solution had been achieved given that requirements and constraints are so malleable. Such logistic considerations mean that designers are more likely to develop satisfactory solutions rather than optimal ones - a notion neatly captured by Simon's (e.g., 1969) concept of 'satisficing'. When implemented effectively, satisficing reflects a strategic balancing act that involves a problem solver engaging in adequate search and exploration of alternative solution ideas to identify one that is better than its competitors without spending too much time engaged in such exploration, otherwise productive activity could falter. To what extent does design involve a satisficing approach? We look at this issue in more detail below by reviewing evidence relating to solution generation and evaluation processes in design. 


\subsection{Attachment to early ideas and limited consideration of alternative solution concepts}

The value of a satisficing approach to design (Simon, 1969) is that it ensures that a 'good enough' solution concept is identified from a range of alternatives. Evidence suggests, however, that designers often focus on 'single' solution ideas and fail to consider and evaluate alternative options (see Ball, Lambell, Reed, \& Reid, 2001, for a review of early research on this issue). This limited consideration of alternatives arises from the very outset of design activity, with designers showing early attachment to initial solution ideas whether these are thought of as conjectures, primary generators, frames or paradigms. One pioneering study by Kant (1985) revealed that expert algorithm designers rapidly developed a single 'kernel' idea that was progressively refined through levels of increasing detail. Similar evidence for an attachment to initial design ideas and a lack of exploration of alternative concepts has been reported in software engineering (e.g., Adelson \& Soloway 1986; Guindon 1990; Jeffries, Turner, Polson, \& Atwood 1981), mechanical engineering (e.g., Ullman et al.,1988), architecture (e.g., Rowe, 1987) and electronic engineering (e.g., Ball, Evans, \& Dennis 1994; Ball, Maskill, \& Ormerod 1998). These studies cut across different design domains and transcend different problem types and levels of expertise, suggesting that the limited generation of alternative solution ideas is a generic feature of designers' natural practices.

As mentioned by Cross (2001), however, it could be that good designers either: (i) produce adequate concepts from the outset such that these do not need to be altered radically during subsequent design development; or (ii) are adept at modifying concepts to ensure that they are satisfactory even if weaknesses arise during subsequent development. There is credibility to both possibilities, especially in the case of highly expert designers, who are likely to have good solution ideas as well as the experience and skills to enhance these even if weaknesses become evident. Indeed, a recent study by Kazakci, Gillier, Piat, and Hatchuel (2014) revealed that when solving real-life design tasks, those professional design teams that generated fewer initial ideas also generated better final design solutions. That said, there is also evidence that even experienced designers can be reluctant to give up design ideas when they are a long way off from being satisfactory. For example, Ullman et al. (1988; Ullman, Stauffer, \& Dietterich, 1987) observed that expert designers would 'patch' weak designs rather than discard them to pursue new concepts. As they note, "The first idea was almost sacred, and sometimes even highly implausible patches would be applied to make it work" (Ullman et al., 1987, p. 16). Similarly, in team-innovation contexts individuals show an overzealous preference (i.e., 'ownership bias') for their own ideas over the potentially better ideas of others (Onarheim \& Christensen, 2012).

Evidence from Fricke $(1996,1999)$ suggests that the tendency for designers to generate alternative concepts may be modulated by the degree of precision present in the given design problem. When the design problem was specified with high precision then designers generated more solution alternatives than when the design problem for the same task was imprecise. This evidence is fascinating from the perspective of metacognitive monitoring and control as it suggests that designers readily modulate their solution-generation activity to meet the demands of the problem; the more active development of a single, fixed concept for an imprecise problem gives rise to a problem frame that focuses subsequent activity, whereas precisely defined problems facilitate exploration of alternative ideas to identify a preferred solution. 


\subsection{Solution fixation and solution inspiration}

Another form of limited solution exploration in design concerns the phenomenon of 'fixation', whereby example solution concepts constrain a designer's imagination. The classic demonstration of design fixation was reported by Jansson and Smith (1991), who conducted a laboratory-based study in which senior design students and professional designers produced solutions for written design briefs. A subset of the participants also received pictures of existing solutions alongside these briefs. These latter designers repeated many more features of the exemplar solutions in their own designs than did those who only received the written briefs, even when these features undermined solution success. Since Jansson and Smith's (1991) original demonstration of design fixation, numerous studies have used a similar experimental paradigm to replicate the effect and explore the conditions influencing its emergence, for example, through manipulations of properties of presented examples (e.g., their richness, uncommonness or modality) and differences in design expertise (see Crilly, $2019 b$, for a state-of-the-art review).

Another line of research related to studies of design fixation has examined how presented examples may serve as 'analogies' to inspire creative idea generation in design (e.g., Casakin \& Goldschmidt, 1999; Goel, 1997; Helms, Vattam, \& Goel, 2009). The examples used in 'design-by-analogy' studies are potentially beneficial, which is a different approach to that sometimes taken in design-fixation research, where examples may not meet task requirements. Design-by-analogy studies also typically present examples that are uncommon and remote from the target design domain (e.g., the analogies may be from biology whilst the target domain is engineering; e.g., Yargin, Firth, \& Crilly, 2018). Furthermore, various procedural factors are manipulated in design-by-analogy studies, such as the number of examples and the timing of presentation (i.e., before vs. during problem solving).

Studies examining design fixation and design-by-analogy have revealed inconsistent findings regarding the fixating versus inspiring effects of examples - a conclusion also drawn by Vasconcelos and Crilly (2016), whose review of 25 studies revealed how the use of diverse methods has engendered equally diverse findings (cf. Crilly, 2019b). However, Sio, Kotovsky, and Cagan (2015) reported a systematic meta-analysis of 43 studies of design fixation and design-by-analogy that revealed some regularities in observed effects, including evidence that providing examples triggers more example-related ideas and fewer categories of ideas, but with ideas also having greater 'novelty'. There was also a positive correlation between the quality of generated ideas and the degree of borrowing from the examples. Moreover, the facilitatory effect of examples on novelty and quality increased with the presentation of fewer and less common prior examples. Interestingly, there was no correlation between the quantity and quality of solution ideas, again challenging the view that generating more ideas increases the chance of a good solution. Sio et al. (2015) additionally identified a significant 'timing' effect, whereby presenting examples at the beginning of design rather than during design produced a larger positive impact on solutions, which is consistent with the observation that after a period of initial design work designers are reluctant to discard an idea they are committed to. This timing effect is opposite to that reported by Moss, Kotovsky, and Cagan $(2007,2011)$, which indicated that cues were more effective when presented after initial design work than beforehand. Other research by Tseng, Moss, Cagan, and Kotovsky (2008), however, has suggested that only examples from 'far' domains and not 'near' ones are beneficial when presented after initial work, with the reverse being the case for examples presented at the beginning of the design task. 
Sio et al.'s (2015) meta-analytic findings speak more to the inspiring effects of examples for design success than their negative, fixating effects. Indeed, it seems that presenting a single, uncommon example may encourage designers to engage in a metacognitive shift from traversing between different parts of the problem space to conducting a deeper search in a specific, remote domain, facilitating the generation of high-quality, novel ideas. As a caveat, however, we note that Sio et al. (2015) restricted their sample to a subset of experiments, such that their analysis might be statistically underpowered with respect to the range of fixation effects considered, rendering their observations in need of validation. Sio et al. also only included studies involving 'non-negative examples' that did not breach requirements for target design problems, which may further limit their conclusions. Notwithstanding these issues, however, Sio et al.'s findings resonate with observations arising in Alipour, Faizi, Moradi, and Akrami's (2017) integrative review of 50 studies of fixation and inspiration effects in design, which likewise indicated that uncommon examples that are an appropriate distance from the target design problem can to mitigate fixation effects.

In considering fixation and inspiration in design we finally note Crilly's (2019a) concern that reviews focusing on experimental studies of these effects typically fail to attend to real-world design practices. This is an important point as one may expect to find key differences between design 'in the lab' versus design 'in the wild (Ball \& Christensen, 2018; Cash, Hicks, \& Culley, 2013). We therefore repeat Crilly's call for more systematic case studies of fixation and inspiration in real-world projects and we welcome Crilly and Firth's (2019) presentation of three 'best practice' case studies that reveal how fixation and 'defixation' should be viewed as ongoing processes rather than momentary events (e.g., an idea that is being fixated might have represented a 'breakthrough' at an earlier point).

\subsection{Self-generated analogies and creative idea generation}

In contrast to research examining how examples and analogies influence design creativity, another literature instead focuses on the role of spontaneous analogising in design, where analogies are self-generated by designers. Studies of real-world design by Visser (1996a, 1996b) and Ball, Ormerod, and Morley (2004) demonstrated that self-generated analogies are an important feature of innovative design. Christensen and Schunn's (2007) 'in vivo' examination of team discussions in a company specialising in the design of medical plastics again found analogising to be a frequent strategy, with analogies serving three primary functions: problem identification, problem solving and explaining. When analogies were coded for their 'distance' from medical plastics, within-domain (or 'near') analogies prevailed during problem identification, whereas between-domain (or 'far') analogies prevailed during explanation. Solution generation was characterised by an equal distribution of within-domain and between-domain analogies.

In follow-up work in engineering design, Ball and Christensen (2009) identified that most spontaneously generated analogies were between-domain, indicating their value for innovative idea generation in a highly creative design project. Analogies were evenly distributed across solution generation, explanation and 'function finding' (i.e., searching for novel functions for the design concept), with just a few arising for problem understanding. The most striking finding, however, was that analogising was closely associated with conditions of subjective uncertainty, as indexed by designers' use of 'hedge words' (e.g., maybe, perhaps, not sure). A temporal analysis of analogising episodes in relation to expressions of uncertainty clarified that analogising reduced uncertainty back to baseline values. Ball and Christensen concluded that analogising is a design strategy under 
metacognitive control, which is triggered by feelings of uncertainty regarding how to progress a design solution. Once deployed, analogising serves to support the continuity of design activity whilst also reducing subjective uncertainty. Chan, Paletz, and Schunn (2012) confirmed Ball and Christensen's (2009) observations regarding the close temporal coupling between subjective uncertainty and analogising, albeit in the domain of scientific problem solving. They used a time-lagged logistic regression approach to reveal that uncertainty increases prior to analogising, maintains an elevated level during analogising and returns to a baseline level just after analogising.

In other research, Casakin, Ball, Christensen, and Badke-Schaub (2015) showed that analogising in team-based design not only ensures progress, but additionally fulfils a social function by engendering enhanced team cohesion and improved collaboration. In another recent study, Christensen and Ball (2016) examined how designers' unique domain knowledge can fuel analogy-based creativity in heterogeneous teams where members had disparate educational backgrounds relating to different design domains. The analysis revealed that analogies that 'matched' (rather than 'mismatched') the educational backgrounds of team members were generated and revisited more frequently, presumably because they were more accessible. Matching analogies were also associated with increased uncertainty, perhaps because domain experts appreciated the challenges involved in mapping such analogies to the current task. Christensen and Ball (2016) concluded that diverse knowledge in teams is beneficial for novel idea generation, which is often mediated through the production of analogies (cf. Menold \& Jablokow's, 2019, evidence that 'cognitive style diversity' in teams can positively impact design quality). Self-generated analogies also appear to have important associations with problem-solution co-evolution in design teams. This was evident in Wiltschnig et al.'s (2013) study, which revealed that co-evolution episodes were more likely to arise contemporaneous with creative analogising, with a predicted link also observed between co-evolution, analogising and expressions of uncertainty. Analogising was seen to be especially dominant in co-evolution episodes pertaining to solution generation, attesting to the key role of analogising in creative ideation in situations of uncertainty.

\subsection{Mental simulation and idea evaluation}

'Mental simulation' is another design strategy that is critical for evaluating the viability of emerging creative ideas (Ball \& Christensen, 2009). In this strategy a sequence of interdependent events is consciously enacted or 'run' in a dynamic mental model to determine cause-effect relationships and predict likely outcomes (Nersessian, 2002). The mental models that underpin mental simulation involve qualitative rather than quantitative reasoning, such that mental simulation provides a quick and economical way for a designer to test a developing idea, including how a design component might function under changed circumstances or with altered features. Mental simulation can also extend to imagining the way in which end-users might interact with an artefact or system.

In their study of medical product design, Christensen and Schunn (2009) identified instances of mental simulation to test three assumptions, namely, that mental simulations: (i) are run in situations associated with subjective uncertainty; (ii) inform reality through inferences that reduce uncertainty; and (iii) have a role that is approximate and inexact. They provided support for all three assumptions: initial representations in simulations had higher than baseline levels of uncertainty; uncertainty was reduced after the simulation run; and resulting representations contained more approximate references than either baseline data or initial representations. These findings were replicated in Ball and Christensen's (2009) study of 
innovative, team-based product design and in Ball, Onarheim, and Christensen's (2010) study of collaborative software design. Both studies strengthened evidence for the claim that mental simulation, like analogical reasoning, is a strategy triggered by metacognitive feelings of uncertainty that serves to progress design activity (especially the evaluation of potential design ideas) whilst also reducing uncertainty. Indeed, Ball et al.'s (2010) study provided evidence that mental simulation was particularly prevalent for solution ideas generated in response to the highest-complexity (i.e., most uncertain) requirements.

\section{The global organisation of cognitive processes in design}

We have considered various aspects of the organisation of cognitive processes in design, such as the way that design often involves an iterative process of problem-solution co-evolution. In addition, we have examined how subjective uncertainty appears to trigger metacognitive control processes that deploy strategies such as analogising and mental simulation to facilitate design progress. We return later to consider the important role played by uncertainty in design, but we first examine the organisation of design activity from a global perspective in relation to its inherent problem/sub-problem structure and the way problems and subproblems are tackled to engender a final, integrated design solution.

\subsection{Breadth-first, depth-first and opportunistic design development}

The complexity of most design problems necessitates some form of 'divide-and-conquer' or 'problem reduction' approach, whereby designers identify how the overarching problem can be split into relatively independent but nevertheless interlinked sub-problems that can be worked on so that an effective, integrated solution can be developed (e.g., Goel \& Pirolli, $1989,1992)$. Pioneering studies in the 1980s presented a view of design as involving systematic, top-down, hierarchical problem reduction and solution development. For example, Jeffries et al.'s (1981) software-design study found that experts and novices tackled design tasks using a top-down, problem-reduction approach that entailed the modular development of the program from abstract design levels through levels of increasing detail. Jeffries et al. noted, however, that the experts' schedule for tackling sub-problems was predominantly 'breadth-first', whereas the novices' schedule was predominantly 'depth-first'.

A breadth-first strategy has two key characteristics (Ball \& Ormerod, 1995). First, the overarching design problem is reduced to several sub-problems relating to specific design goals. Second, these sub-problems are tackled a full level at a time, potentially producing sub-sub-problems whose development is postponed until all sub-sub-problems at that new level have been identified. This design approach is 'balanced' (Adelson \& Soloway, 1986) in that the whole solution to the overarching design problem develops in an integrated manner through each level of abstraction. In contrast, the depth-first strategy entails taking one toplevel sub-problem at a time and developing it in detail before then moving onto do the same with each of the remaining top-level sub-problems in turn (Ball \& Ormerod, 1995). This strategy is less effective than a breadth-first one because it requires costly backtracking if current solution ideas are incompatible with earlier ones. Nevertheless, the depth-first strategy is advantageous for facilitating early resolution of whole branches of the problem/sub-problem tree. Indeed, a noteworthy observation from Jeffries et al.'s (1981) study was that some experts periodically deviated from a breadth-first strategy, with such deviations involving the in-depth development of a solution to meet a high-level subproblem, especially when this sub-problem was perceived to be complex, unfamiliar or important. Thus, while these experts were still operating in a top-down manner they were 
mixing breadth-first and depth-first design strategies in a context-sensitive way that was flexible yet effective.

In the early 1990s a new wave of research made contrasting claims to the view of design as a predominantly structured, top-down activity, with several authors proposing that both novice and expert designers are highly unstructured. For example, Guindon (1990) noted that the software engineers she studied exhibited 53\% of activities that deviated from top-down, breadth-first design. Visser (1990) claimed that while the expert designer she studied described himself as 'intending' to pursue a top-down, depth-first strategy his behaviour revealed considerable deviation from a structured approach. Accordingly, solutiondevelopment processes in design started to be described as 'opportunistic' to emphasise the way in which designers take immediate advantage of solution opportunities. However, not all studies in the 1990s supported this view. Ball and Ormerod (1995), Ball et al. (1994), Ball, Evans, Dennis, and Ormerod (1997) and Davies (1991) presented evidence showing that design may best be viewed as predominantly top-down and structured but with 'opportunistic episodes' arising to circumvent design impasses or knowledge deficits as well as to capitalise on emerging opportunities. The current consensus is that design involves an adaptive combination of both structured and opportunistic processing (cf. Visser, 1994, 2006). This adaptive and dynamic view of the organisation of design activity is fundamentally metacognitive in its emphasis as it acknowledges the way in which ongoing monitoring and control processes can trigger deviations from a structured approach, for example, when designers are faced with uncertainty.

In line with an adaptive account of the organisation of design processing, Ball et al. (1997) suggested that although the preferred strategy of expert designers is a top-down, breadth-first one, designers will typically switch to depth-first design to deal strategically with situations where their knowledge is stretched. Depth-first design is, therefore, a response to factors such as problem complexity and design uncertainty, with detailed exploration of solution ideas allowing designers to assess and gain confidence in the viability of uncertain concepts. This account was supported by Ball et al.'s (2010) study of software design teams, which revealed that designers produced an initial 'first-pass' solution to the given design brief in a breadthfirst manner, with this solution addressing several 'easy-to-handle' requirements. The designers then focused on adding 'complex-to-handle' requirements to this initial solution, which were also linked to heightened feelings of uncertainty. They then developed solutions to these complex requirements in a depth-first manner.

\subsection{Metacognitive monitoring and control in design and the role of uncertainty}

Considerations relating to the global organisation of cognitive processing in design bring metacognition to centre stage given its role in orchestrating the moment-by-moment monitoring and control of strategic processing. A metacognitive view of design aligns closely with Schön's (1983) insights relating to the way in which design involves 'reflective practice', whereby expert designers exhibit a 'a kind of knowing-in-practice'. Such knowledge is largely tacit, implicit and intuitive and therefore different to explicit, conventionalised knowledge of design rules and tactics as found in textbooks describing design methods. In advancing his theoretical framework of reflective practice, Schön (1983) also identified another key process of 'reflection-in-action', which he viewed as the 'intelligence' that guides intuitive behaviour in contexts such as real-world design. 
Schön's notion of reflection-in-action has clear resonances with the concept of metacognition as captured in the 'metareasoning framework' espoused by Ackerman and Thompson (2017, 2018). According to this model, metacognitive monitoring and control processes in thinking and reasoning are highly attuned to subjective feelings of certainty/uncertainty, including socalled 'judgments of solvability' (i.e., estimates of the probability of successfully finding a solution to a problem), 'feelings of warmth' or 'intermediate confidence' (i.e., beliefs that one is on the right track toward an effective solution concept), 'feelings of rightness' (i.e., beliefs that a solution is effective or needs further development) and 'final judgments of solvability' or 'final confidence' (i.e., the sense that a problem has been solved successfully). We contend that Ackerman and Thompson's metareasoning framework is highly relevant to understanding the evidence that we have reviewed on the nature of cognitive strategies in design, whether these relate to problem understanding, idea generation or solution evaluation. Indeed, much of the evidence discussed places designers' subjective assessments of uncertainty at the very heart of their decision making relating to the deployment of strategies such as analogical reasoning, mental simulation or depth-first design development.

In advancing a metacognitive understanding of design, we propose that a designer's experience of heightened subjective uncertainty can act as a 'metacognitive trigger' to catalyse a change to a more elaborate and deliberative reasoning strategy than arises when they feel confident about ongoing processing. Analogising and mental simulation are two strategies that can be viewed as involving more elaborate and deliberative reasoning. Similar ideas have been proposed by Stempfle and Badke-Schaub (2002) in relation to a study of design-team thinking that coded for expressions of uncertainty. Their findings suggested that simpler design problems were associated with team self-efficacy and rapid, intuitive evaluative reasoning, whereas complex design problems triggered a shift towards a process of effortful idea generation and analysis. In other research, Paletz, Chan, and Schunn (2017) showed how uncertainty in design teams often triggers 'micro-conflicts' that involve effortful and deliberative 'oppositional' or argumentative reasoning between team members.

Interestingly, such micro-conflicts were followed by reduced uncertainty in successful design teams but led to increased uncertainty in unsuccessful teams.

We also propose that subjective uncertainty in design is constantly fluctuating, such that at one moment designers may feel confident in their progress, whilst at another moment they may hit an impasse or lose faith in the viability of an emerging idea. In this way, design cognition can alternate between periods of stable strategy deployment and sudden strategy change triggered by momentarily increased uncertainty. The idea of fluctuating feelings of uncertainty driving a metacognitive 'switch' mechanism is gaining widespread acceptance in reasoning research (e.g., Ackerman \& Thompson 2014; Ball \& Stupple 2016; Thompson, Prowse Turner, \& Pennycook 2011; Thompson et al. 2013). Related ideas have also been advanced within entrepreneurship research in terms of understanding how individuals identify entrepreneurial opportunities and act upon them flexibly (McMullen \& Shepherd, 2006). In this regard, an 'entrepreneurial mindset' has been defined as the ability to be adaptive, flexible, and self-regulating in one's cognitive-strategy application given dynamic and uncertain task environments (Haynie, Shepherd, Mosakowski, \& Earley, 2010). Differences in performance on entrepreneurial tasks may thus partly be explained by the role that metacognition plays in promoting cognitive adaptability.

It is also becoming clear that strategic decisions that are based on metacognitive experiences are often determined by relative rather than absolute perceptions of perceived uncertainty (Wänke \& Hansen 2015), with dynamic shifts between perceived certainty and perceived 
uncertainty being critical for triggering strategy change. These ideas align with Christensen and Ball's (2018) claim that in some design contexts epistemic uncertainty may fluctuate extensively, with periodic bouts of uncertainty leading to immediate, creative processing, whereas in other design contexts epistemic uncertainty may provide a more global and stable backdrop to ongoing activity, potentially leading to isolated moments of certainty triggering creative processing. This more nuanced account of metacognitive effects in design seems to be needed to explain some unexpected effects observed by Christensen and Ball (2018) in a study of collaborating designers tackling a complex, cross-cultural design task, where subjective 'certainty' rather than uncertainty was associated with immediate creative reasoning and information elaboration, although, as expected, subjective uncertainty predicted subsequent returns to unresolved issues.

\section{Prospects for research on design cognition and design metacognition}

Our review of the status of research on design cognition and design metacognition, although selective and at times inconsistent, nevertheless provides a valuable snapshot of our contemporary understanding of information processing in design. The inconsistency that arises is unsurprising given the multiplicity of factors that can impact upon design cognition, including differences in the background experience and expertise of designers, differences in whether studies are examining individual or collaborative design, differences in design domains and the nature and complexity of the tasks being tackled, differences in the methodologies adopted to study design cognition in the first place and differences in a whole host of other variables such as the presence of prior examples and analogies or the engagement of clients and stakeholders. Indeed, given the many, often uncontrolled factors that can permeate studies of design cognition, it is, perhaps, the overall consistency in findings that is most remarkable, hinting at the possibility that design is underpinned by a set of core processes, including ones we have highlighted such as conjecture-based problem formulation, problem-solution co-evolution, analogical reasoning, mental simulation and targeted solution generation.

With respect to research on the fixating or inspiring effects of prior examples and analogies on creative design, the extant evidence suggests a positive view, whereby fixation may be of benefit to design ideation, especially when single examples are presented that are 'uncommon' and from remote domains such that they encourage designers to explore a novel solution space in depth. As studies of fixation and inspiration in design progress it would be valuable to see greater methodological consistency (cf. Crilly, 2019b; Vasconcelos \& Crilly, 2016). In addition, we concur with Crilly's (2019a) plea for more systematic case studies of real-world design that are targeted at exploring the nature of inspiration and fixation effects in individual and team-based design practice. Such case studies are a vital aspect of a multimethod research endeavour in which ecological validity is essential to corroborate or challenge findings emerging from laboratory-based, experimental studies.

A further, consistent observation emerging from our review relates to the role of subjective uncertainty as a trigger for metacognitive control processes to switch ongoing processing in new directions through the application of strategies such as analogising, mental simulation and depth-first idea exploration. We contend that metacognition has been an overlooked aspect of information processing in design, despite being central to understanding every aspect of a designer's ongoing activity in progressing from an initial ill-defined design problem to an all-encompassing design solution. We argue that viewing design cognition through a metacognitive lens is critical to advancing an integrated understanding of the way 
in which strategies change over the design timecourse in response to fluctuating feelings of uncertainty. That said, understanding the metacognitive basis of the dynamic aspects of design cognition is in its infancy, with many core questions still needing to be addressed. For example, it is unclear how best to measure subjective uncertainty in design. The analysis of 'hedge words' in think-aloud protocols or design conversations is compelling but suffers from the occurrence of such terms as simple 'politeness markers', which can be difficult to spot and remove. An alternative approach would be to solicit 'feeling of warmth' or 'confidence' ratings continuously during design activity, but this could be invasive and reactive, changing 'natural' design activity.

Other challenges for developing a metacognitive understanding of design relate to issues discussed by Christensen and Ball (2018), whereby it can be hard to predict whether it is subjective uncertainty or subjective certainty that will drive design strategies as well as creative idea generation. To have a predictive model of the way in which certainty or uncertainty trigger design strategies is a goal that we are a long way from attaining, although it is clear that such a model will need to be attuned to the fact that uncertainty is a 'relative' state that can only be measured in terms of a prevailing background context. These various challenges to developing a metacognitive understanding of design are not insurmountable and overcoming them is, we believe, critical for achieving a fully encompassing account of design cognition. We welcome the fact that other design researchers are likewise recognising the importance of studying the metacognitive basis of design activity, and we note, for example, the recent work of Cash and Kreye (2018) who have investigated 'uncertainty perception' as a general driver for design activity through an observation-based protocol study. As in our research, Cash and Kreye view design as a process whereby uncertainty triggers activity that thence serves to resolve this uncertainty over time (see also $\mathrm{Yu}$, Honda, Sharqawy, \& Yang, 2016).

We finally note that the selective nature of our review means that we have failed to cover some important aspects of design cognition, one of which is the core role played by sketching in problem understanding and idea generation (e.g., Goel, 1995; Goldschmidt, 1991;

McGown, Green, \& Rodgers, 1998; Schön \& Wiggins, 1992). We see sketching as a key area of design cognition that would benefit from in-depth studies of its metacognitive dimensions. Indeed, we note that preliminary research on this topic (Kavakli, Scrivener, \& Ball, 1998; Scrivener, Ball, \& Tseng, 2000) demonstrated how uncertainty is a trigger for strategic switches in designers' modes of sketching, engendering transitions from structurally-oriented sketching (e.g., depicting design elements) to functionally-oriented sketching (e.g., reflecting the connectivity between elements and their integrated behaviour).

We acknowledge that our review likely suffers from other omissions, many of which will have arisen inadvertently because of the sheer expansion in design-cognition research since the 1960s. The seemingly exponential growth in cognitively-oriented design research over the past few decades is certainly a positive development, although one that also brings challenges in terms of conceptual fragmentation. We therefore conclude with a call for greater efforts toward integrative, theory-driven research on design cognition (cf. Cash, 2018), which can itself be facilitated by contemporary reviews that identify common findings and general principles. We trust that the present review is a useful step in this direction, particularly with its focus on proposing a generic account of how strategic shifts in design processing may be based on metacognitive control decisions driven by designers' fluctuating feelings of uncertainty. 


\section{References}

Ackerman, R., \& Thompson, V. A. (2014). Meta-reasoning: What can we learn from metamemory. In A. Feeney \& V. A. Thompson (Eds.), Reasoning as memory (pp. 164182). Hove: Psychology Press.

Ackerman, R., \& Thompson, V. A. (2017). Meta-reasoning: Monitoring and control of thinking and reasoning. Trends in Cognitive Sciences, 21, 607-617.

Ackerman, R., \& Thompson, V. A. (2018). Meta-reasoning: Shedding meta-cognitive light on reasoning research. In L. J. Ball \& V. A Thompson (Eds.), The Routledge international handbook of thinking and reasoning (pp. 1-15). Abingdon, Oxon: Routledge.

Adams, R., Aleong, R., Goldstein, M., \& Solis, F. (2018). Rendering a multi-dimensional problem space as an unfolding collaborative inquiry process. Design Studies, 57, 37-74.

Adelson, B., \& Soloway, E. (1986). A model of software design. International Journal of Intelligent Systems, 1, 195-213.

Akin, O. (1978). How do architects design? In J. C. Latombe (Ed.), Artificial Intelligence and Pattern Recognition in Computer Aided Design (pp. 65-98). New York, NY: NorthHolland Publishing Company,

Alipour, L., Faizi, M., Moradi, A. M., \& Akrami, G. (2017). A review of design fixation: Research directions and key factors. International Journal of Design Creativity \& Innovation, 6, 1-14.

Atman, C. J., Chimka, J. R., Bursic, K. M., \& Nachtmann, H. L. (1999). A comparison of freshman and senior engineering design processes. Design Studies, 20, 131-152.

Ball, L. J., \& Christensen, B. T. (2009). Analogical reasoning and mental simulation in design: Two strategies linked to uncertainty resolution. Design Studies, 30, 169-186.

Ball, L. J., \& Christensen, B. T. (2018). Designing in the wild. Design Studies, 57, 1-8.

Ball, L. J., Evans, J. St. B. T, \& Dennis, I. (1994). Cognitive processes in engineering design: A longitudinal study. Ergonomics, 37, 1753-1786.

Ball, L. J., Evans, J. St. B. T., Dennis, I., \& Ormerod, T. C. (1997). Problem-solving strategies and expertise in engineering design. Thinking \& Reasoning, 3, 247-270.

Ball, L. J., Lambell, N. J., Reed, S. E., \& Reid, F. J. M. (2001). The exploration of solution options in design: A 'Naturalistic Decision Making' perspective. In P. Lloyd, \& H. Christiaans (Eds.), Designing in Context (pp. 79-93). Delft, The Netherlands: Delft University Press.

Ball, L. J., Maskill, L., \& Ormerod, T. C. (1998). Satisficing in engineering design: Causes, consequences and implications for design support. Automation in Construction, 7, 213 227. 
Ball, L. J., Onarheim, B., \& Christensen, B. T. (2010). Design requirements, epistemic uncertainty and solution development strategies in software design. Design Studies, 31, 567-589.

Ball, L. J., \& Ormerod, T. C. (1995). Structured and opportunistic processing in design: A critical discussion. International Journal of Human-Computer Studies, 43, 131-151.

Ball, L. J., \& Ormerod, T. C. (2000). Applying ethnography in the analysis and support of expertise in engineering design. Design Studies, 21, 403-421.

Ball, L. J., Ormerod, T. C., \& Morley, N. J. (2004). Spontaneous analogising in engineering design: A comparative analysis of experts and novices. Design Studies, 25, 495-508.

Ball, L. J., \& Stupple, E. J. N. (2016). Dual reasoning processes and the resolution of uncertainty: The case of belief bias. In L. Macchi, M. Bagassi, \& R. Viale (Eds.), Cognitive unconscious and human rationality (pp. 143-165). Cambridge, MA: MIT Press.

Casakin, H., Ball, L. J., Christensen, B. T., \& Badke-Schaub, P. (2015). How do analogizing and mental simulation influence team dynamics in innovative product design? AI EDAM, 29, 173-183.

Casakin, H., \& Goldschmidt, G. (1999). Expertise and the use of visual analogy: Implications for design education. Design Studies, 20, 153-175.

Cash, P. J. (2018). Developing theory-driven design research. Design Studies, 56, 84-119.

Cash, P. J., Hicks, B. J., \& Culley, S. J. (2013). A comparison of designer activity using core design situations in the laboratory and practice. Design Studies, 34, 575-611.

Cash, P., \& Kreye, M. (2018). Exploring uncertainty perception as a driver of design activity. Design Studies, 54, 50-79.

Chan, J., Paletz, S. B., \& Schunn, C. D. (2012). Analogy as a strategy for supporting complex problem solving under uncertainty. Memory \& Cognition, 40, 1352-1365.

Christensen, B. T., \& Ball, L. J. (2014). Studying design cognition in the real world using the 'in vivo' methodology. In P. Rogers \& J. Yee (Eds.), The Routledge companion to design research (pp. 317-328). London: Routledge.

Christensen, B. T., \& Ball, L. J. (2016). Creative analogy use in a heterogeneous design team: The pervasive role of background domain knowledge. Design Studies, 46, 38-58.

Christensen, B. T., \& Ball, L. J. (2018). Fluctuating epistemic uncertainty in a design team as a metacognitive driver for creative cognitive processes. CoDesign, 14, 133-152.

Christensen, B. T., \& Schunn, C. D. (2007). The relationship of analogical distance to analogical function and preinventive structure: The case of engineering design. Memory \& Cognition, 35, 29-38. 
Christensen, B. T., \& Schunn, C. D. (2009). The role and impact of mental simulation in design. Applied Cognitive Psychology, 23, 327-344.

Christiaans, H. H. C. M., \& Dorst, K. H. (1992). Cognitive models in industrial design engineering: A protocol study. In D. L. Taylor \& D. A. Stauffer (Eds.), Design theory and methodology-DTM92 (pp. 131-140). New York, NY: ASME.

Cramer-Petersen, C. L., Christensen, B. T., \& Ahmed-Kristensen, S. (2019). Empirically analysing design reasoning patterns: Abductive-deductive reasoning patterns dominate design idea generation. Design Studies, 60, 39-70.

Crilly, N. (2019a). Creativity and fixation in the real world: A literature review of case study research. Design Studies.

Crilly, N. (2019b). Methodological diversity and theoretical integration: Design fixation research as an example of fixation in research design? Design Studies, this issue.

Crilly, N., \& Firth, R. M. (2019). Creativity and fixation in the real world: Three case studies of invention, design and innovation. Design Studies.

Cross, N. (1993). Science and design methodology: A review. Research in Engineering Design, 5, 63-69.

Cross, N. (1997). Descriptive models of creative design: Application to an example. Design Studies 18, 427-440.

Cross, N. (2001). Design cognition: Results from protocol and other empirical studies of design activity. In C. Eastman, M. McCracken, \& W. Newstetter (Eds.), Design knowing and learning: Cognition in design education (pp. 79-103). Oxford: Elsevier Science.

Cross, N. (2007). Forty years of design research. Design Studies, 1, 1-4.

Cross. N. (2018). Developing design as a discipline. Journal of Engineering Design, 29, 691708.

Cross, N., Christiaans, H., \& Dorst, K. (Eds.) (1996). Analysing design activity. Chichester: John Wiley \& Sons.

Cross, N., \& Clayburn Cross, A. C. (1998). Expertise in engineering design. Research in Engineering Design, 10, 141-149.

Cross, N., \& Dorst, K. (1998). Co-evolution of problem and solution spaces in creative design: Observations from an empirical study. In J. S. Gero \& M. L. Maher (Eds.), Computational models of creative design IV. New South Wales, Australia: University of Sydney.

Darke, J. (1979). The primary generator and the design process. Design Studies, 1, 36-44. 
Davies, S. P. (1991). Characterising the program design activity: Neither strictly top-down nor globally opportunistic. Behavior \& Information Technology, 10, 173-190.

Dong, A., Lovallo, D., \& Mounarath, R. (2015). The effect of abductive reasoning on concept selection decisions. Design Studies, 37, 37-58.

Dorst, K. (2011). The core of 'design thinking' and its application. Design Studies, 32, 521532.

Dorst, K. (2019). Modelling co-evolution. Design Studies, this issue.

Dorst, K., \& Cross, N. (2001). Creativity in the design process: Co-evolution of problemsolution. Design Studies, 22, 425-437.

Eastman, C. M. (1970). On the analysis of intuitive design processes. In G. T. Moore (Ed.), Emerging Methods in Environmental Design \& Planning (pp. 21-37). Cambridge, MA: MIT Press.

Fricke, G. (1996). Successful individual approaches in engineering design. Research in Engineering Design, 8, 151-165.

Fricke, G. (1999). Successful approaches in dealing with differently precise design problems. Design Studies, 20, 417-429.

Goel, A. K. (1997). Design, analogy, and creativity. IEEE Expert, 12, 62-70.

Goel, V. (1995). Sketches of thought. Cambridge, MA: MIT Press.

Goel, V., \& Pirolli, P. (1989). Motivating the notion of generic design within informationprocessing theory: The design problem space. AI Magazine, 10, 18-35.

Goel, V., \& Pirolli, P. (1992). The structure of design problem spaces. Cognitive Science, 16, 395-429.

Goldschmidt, G. (1991). The dialectics of sketching. Creativity Research Journal, 4, 123143.

Guindon, R. (1990). Knowledge exploited by experts during software system design. International Journal of Man-Machine Studies, 33, 279-304.

Haynie, J. M., Shepherd, D., Mosakowski, E., \& Earley, P. C. (2010). A situated metacognitive model of the entrepreneurial mindset. Journal of Business Venturing, 25, 217-229.

Helms, M., Vattam, S. S., \& Goel, A. K. (2009). Biologically inspired design: process and products. Design Studies, 30, 606-622.

Jansson, D. G., \& Smith, S. M. (1991). Design fixation. Design Studies, 12, 3-11. 
Jeffries R., Turner A. A., Polson P. G., \& Atwood M. E. (1981). The processes involved in designing software. In J. R. Anderson (Ed.), Cognitive skills and their acquisition (pp. 255-283). Hillsdale, NJ: Erlbaum.

Kant, E. (1985). Understanding and automating algorithm design. IEEE Transactions on Software Engineering, 11, 1361-1374.

Kazakci, A. O., Gillier, T., Piat, G., \& Hatchuel, A. (2014). Brainstorming versus creative design reasoning: A theory-driven experimental investigation of novelty, feasibility and value of ideas. In J. S. Gero \& S. Hanna (Eds.), Design Computing \& Cognition'14 (pp. 173-188), 1-20. Ney York, NY: Springer.

Kavakli, M., Scrivener, S. A., \& Ball, L. J. (1998). Structure in idea sketching behaviour. Design Studies, 19, 485-517.

Lawson, B. R. (1979). Cognitive strategies in architectural design. Ergonomics, 22, 59-68.

Lloyd, P., \& Oak, A. (2018). Cracking open co-creation: Categories, stories, and value tension in a collaborative design process. Design Studies, 57, 93-111.

Lloyd, P., \& Scott, P. (1994). Discovering the design problem. Design Studies, 15, 125-140.

Lloyd, P., \& Scott, P. (1995). Difference in similarity: Interpreting the architectural design process. Environment and Planning B: Planning \& Design, 22, 383-406.

Maher, M. L. (1994). Creative design using a genetic algorithm. Computing in Civil Engineering, 2, 2014-2021.

Maher, M. L. (2000). A model of co-evolutionary design. Engineering with Computers, 16, 195-208.

Maher, M. L., \& Poon, J. (1995). Co-evolution of the fitness function and design solution for design exploration. In Proceedings of IEEE International Conference on Evolutionary Computing (pp. 240-244). Washington, DC: IEEE.

Maher, M. L., \& Poon, J. (1996). Modeling design exploration as co-evolution. ComputerAided Civil \& Infrastructure Engineering, 11, 195-209.

Maher, M., \& Tang, H. H. (2003). Co-evolution as a computational and cognitive model of design. Research in Engineering Design, 14, 47-63.

McDonnell, J. (2018). Design roulette: A close examination of collaborative decision-making in design from the perspective of framing. Design Studies, 57, 75-92.

McGown, A., Green, G., \& Rodgers, P. A. (1998). Visible ideas: Information patterns of conceptual sketch activity. Design Studies, 19, 431-453.

McMullen, J. S., \& Shepherd, D. A. (2006). Entrepreneurial action and the role of uncertainty in the theory of the entrepreneur. Academy of Management Review, 31, 132-152. 
Menold, J., \& Jablokow, K. (2019). Exploring the effects of cognitive style diversity and selfefficacy beliefs on final design attributes in student design teams. Design Studies, 60, 71102.

Moss, J., Kotovsky, K., \& Cagan, J. (2007). The influence of open goals on the acquisition of problem-relevant information. Journal of Experimental Psychology: Learning, Memory, \& Cognition, 33, 876-891.

Moss, J., Kotovsky, K., \& Cagan, J. (2011). The effect of incidental hints when problems are suspended before, during, or after an impasse. Journal of Experimental Psychology: Learning, Memory, \& Cognition, 37, 140-148.

Nersessian, N. J. (2002). The cognitive basis of model-based reasoning in science. In P. Carruthers \& S. Stich (Eds.), The cognitive basis of science (pp. 133-153). New York, NY: Cambridge University Press.

Onarheim, B., \& Christensen, B. T. (2012). Distributed idea screening in stage-gate development processes. Journal of Engineering Design, 23, 660-673.

Paletz, S. B., Chan, J., \& Schunn, C. D. (2017). The dynamics of micro-conflicts and uncertainty in successful and unsuccessful design teams. Design Studies, 50, 39-69.

Poon, J., \& Maher, M. L. (1997). Co-evolution and emergence in design. Artificial Intelligence in Engineering, 11, 319-327.

Rittel, H., \& Webber, M. (1973). Dilemmas in a general theory of planning. Policy Sciences, $4,155-169$.

Roozenburg, N. F. (1993). On the pattern of reasoning in innovative design. Design Studies, 14, 4-18.

Rowe, P. (1987). Design thinking. Cambridge, MA: MIT Press.

Schön, D. (1983). The reflective practitioner: How professionals think in action. London: Temple Smith.

Schön, D. A., \& Wiggins, G. (1992). Kinds of seeing and their functions in designing. Design Studies, 13, 135-156.

Schurz, G. (2008). Patterns of abduction. Synthese, 164, 201-234.

Scrivener, S. A., Ball, L. J., \& Tseng, W. (2000). Uncertainty and sketching behaviour. Design Studies, 21, 465-481.

Simon, H. A. (1969). The sciences of the artificial. Cambridge, MA: MIT Press.

Simon, H. A. (1973). The structure of ill structured problems. Artificial Intelligence, 4, 181201. 
Sio, U. N., Kotovsky, K., \& Cagan, J. (2015). Fixation or inspiration? A metanalytic review of the role of examples on design processes. Design Studies, 39, 70-99.

Stempfle, J., \& Badke-Schaub, P. (2002). Thinking in design teams: An analysis of team communication. Design Studies, 23, 473-496.

Thomas, J. C., \& Carroll, J. M. (1979). The psychological study of design. Design Studies, 1, $5-11$.

Thompson, V. A., Prowse-Turner, J. A., \& Pennycook, G. (2011). Intuition, reason, and metacognition. Cognitive Psychology, 63, 107-140.

Thompson, V. A., Prowse-Turner, J., Pennycook, G. R., Ball, L. J., Brack, H. M., Ophir, Y., \& Ackerman, R. (2013). The role of answer fluency and perceptual fluency as metacognitive cues for initiating analytic thinking. Cognition, 128, 237-251.

Tseng, I., Moss, J., Cagan, J., \& Kotovsky, K. (2008). The role of timing and analogical similarity in the stimulation of idea generation in design. Design Studies, 29, 203-221.

Ullman, D. G., Dietterich, T. G., \& Stauffer, L. A. (1988). A model of the mechanical design process based on empirical data. Artificial Intelligence for Engineering Design, Analysis \& Manufacturing, 2, 33-52.

Ullman, D. G., Stauffer, L. A., \& Dietterich, T. G. (1987). Preliminary results of an experimental study on the mechanical design process. Technical Report X6-30-9, Oregon State University.

Valkenburg, R., \& Dorst, K. (1998). The reflective practice of design teams. Design Studies, 19, 249-271.

Vasconcelos, L. A., \& Crilly, N. (2016). Inspiration and fixation: Questions, methods, findings, and challenges. Design Studies, 42, 1-32.

Visser, W. (1990). More or less following a plan during design: opportunistic deviations in specification. International Journal of Man-Machine Studies, 33, 247-278.

Visser, W. (1994). Organisation of design activities: opportunistic, with hierarchical episodes. Interacting with Computers, 6, 239-274.

Visser, W. (1996a). Two functions of analogical reasoning in design: A cognitive-psychology approach. Design Studies, 17, 417-434.

Visser, W. (1996b). Use of episodic knowledge and information in design problem solving. In N. Cross, H. Christiaans, and K. Dorst (Eds.), Analysing design activity (pp. 271-289). Chichester: John Wiley \& Sons.

Visser, W. (2006). The cognitive artifacts of designing. Mahwah, NJ: Erlbaum.

Wänke, M., \& Hansen, J. (2015). Relative processing fluency. Current Directions in Psychological Science, 24, 195-199. 
Wiltschnig, S., Christensen, B. T., \& Ball, L. J. (2013). Collaborative problem-solution coevolution in creative design. Design Studies, 34, 515-542.

Yargin, G. T., Firth, R. M., \& Crilly, N. (2018). User requirements for analogical design support tools: Learning from practitioners of bio-inspired design. Design Studies, 58, 135 .

Yu, B. Y., Honda, T., Sharqawy, M., \& Yang, M. (2016). Human behavior and domain knowledge in parameter design of complex systems. Design Studies, 45, 1-26. 